\title{
Gunshot wounds to the penis and scrotum: a narrative review of management in civilian and military settings
}

\author{
Charlotte Goldman ${ }^{1}$, Nathan Shaw ${ }^{1}$, Danelo du Plessis ${ }^{2}$, Jeremy B. Myers ${ }^{3}$, Andre van der Merwe ${ }^{2}$, \\ Krishnan Venkatesan ${ }^{1,4}$
}

${ }^{1}$ Georgetown University School of Medicine, Department of Urology, Washington, DC, USA; ${ }^{2}$ Division of Urology, Department of Surgical Sciences, Stellenbosch University and Tygerberg Academic Hospital, Cape Town, South Africa; ${ }^{3}$ Division of Urology, Department of Surgery, University of Utah, Salt Lake City, UT, USA; ${ }^{4}$ MedStar Washington Hospital Center, Department of Urology, Washington, DC, USA Contributions: (I) Conception and design: K Venkatesan, JB Myers, A van der Merwe; (II) Administrative support: K Venkatesan; (III) Provision of study materials or patients: K Venkatesan, JB Myers, A van der Merwe; (IV) Collection and assembly of data: K Venkatesan, JB Myers, A van der Merwe; (V) Data analysis and interpretation: K Venkatesan, JB Myers, A van der Merwe; (VI) Manuscript writing: All authors; (VII) Final approval of manuscript: All authors.

Correspondence to: Krishnan Venkatesan. 110 Irving St., NW, Suite 3B-19, Washington, DC 20010, USA. Email: krishnan38@gmail.com.

\begin{abstract}
Gunshot wounds (GSW) to the penis and scrotum are present in two thirds of all genitourinary (GU) trauma, with a growing proportion of blast injuries in the military setting. Depending on the energy of the projectile, the injury patterns present differently for military and civilian GSWs. In this review, we sought to provide a detailed overview of GSWs to the external genitalia, from mechanisms to management. We examine how ballistic injury impacts tissues, as well as the types of injuries that occur, and how to assess these injuries to the external genitalia. If there is concern for injury to the deep structures of the penis or scrotum, operative exploration and repair is warranted. Relevant history and physical examination, role of imaging, and choice of conservative or surgical treatment options in the civilian and military setting are discussed, as well as guidelines for management set forth by the American Urological Association (AUA) and European Association of Urology (EAU).
\end{abstract}

Keywords: Genital trauma; gunshot wounds (GSW); genitalia; urologic trauma; ballistic trauma

Submitted Aug 13, 2020. Accepted for publication Sep 08, 2020.

doi: $10.21037 /$ tau-20-1175

View this article at: http://dx.doi.org/10.21037/tau-20-1175

\section{Introduction}

Among all penetrating genitourinary (GU) trauma, $60 \%$ of injuries involve the external genitalia $(1,2)$. While injuries to the external genitalia may result from other mechanisms including accidents, sports injuries, injuries related to sexual activity, and domestic or community violence, penetrating trauma makes up 20-50\% (3). Gunshot wounds (GSW) to the external genitalia represent $\sim 50-90 \%$ of penetrating GU injuries and appear to be increasing in the US and similarly in Africa and parts of Europe (3-8). Furthermore, among military conflicts, damage to the external genitalia has been documented in $60 \%$ of GU injuries with GSWs and blast shrapnel making up the primary mechanism of penetrating trauma $(1,9)$. As more casualties are survived on the frontline, an increasing number of non-lethal injuries, including those to the genitalia require treatment (10).

GSWs can cause devastating injuries to the structures of the penis and scrotum as well as causing significant concomitant injuries to other structures (3). Management of these urologic emergencies hinges on quick and correct identification of the injured structures to allow for the appropriate treatment. In conducting and assembling this review, we sought to provide a single comprehensive source for those caring for patients sustaining GSWs to the external genitalia in a wide range of settings. More than simply summarizing treatment guidelines, we discuss the types and mechanisms of ballistic injuries caused by GSWs to the external genitalia before answering the question of 
how to best assess and treat affected patients in the civilian and military settings. We present the following article in accordance with the Narrative Review Checklist (available at: http://dx.doi.org/10.21037/tau-20-1175).

\section{Methods}

An exhaustive literature search was conducted using PubMed, Medline, and Google Scholar. The references of the resulting collection were further reviewed to identify additional articles of relevance. Keywords searched included: gunshot wounds, external genitalia, urologic trauma, ballistic trauma, civilian and military gunshot wounds, traumatic avulsion, penetrating trauma, and wound healing. Given the importance of both historical and contemporary perspectives on these types of injuries, our literature search included publications from 1968 to present. Any publication that was peer-reviewed and proved a novel or valuable addition to the existing, relatively limited, body of literature on this subject was included. This was additionally tempered with the experience of the authors.

\section{Discussion}

The management of GSWs to the external genitalia, if not all GSWs, must include an understanding of the nature of ballistic injuries, including types of ballistics and the sequence of tissue-level events culminating in injury, before moving on to the consideration of evaluation and management. This review accordingly follows a natural progression from ballistic injury mechanisms, to patient evaluation, followed by specific anatomic considerations in management and lastly discussing high-energy battlefield injuries.

\section{Ballistic injury mechanics}

The ballistic injuries caused by GSWs are unique among penetrating traumas in how the projectile interacts with and injures surrounding tissues. Military literature has described the mechanics of GSWs, which are critical to understand to appropriately repair these tissues (11). While often simplified to high velocity injuries, i.e. rifles, $v s$. low velocity injuries, i.e., handguns, the most important factor in the injury pattern is the energy transferred by the projectile. The energy depends on the projectile's structure, velocity, and distance from which it is fired. The energy (and resultant damage) may also depend on the integrity of the projectile, such as whether it breaks or shatters on impact.
Low energy injuries are more often in a civilian setting while high energy injuries are more commonly seen in the combat setting (1,12-14). High energy tissue damage can result from a low velocity projectile fired at in close range, such as in shotgun injuries, resulting in catastrophic tissue damage. When evaluating a patient who has suffered from a GSW, it is important to obtain a thorough history of the type of weapon, ammunition, and distance at which it was fired to understand the pattern of tissue damage created by the projectile. Furthermore, information on the mechanism may prompt the clinician to investigate other possible concomitant injuries.

The two primary types of tissue damage that are applicable to GU trauma are direct tissue damage and cavitation. Damage from GSW is effectively caused by energy transfer from the projectile to the affected tissue, which is related to deceleration. Spin itself produces added gyroscopic effects, much like a spinning top. These motions are known as precision and nutation and form a combined movement known as yaw: the deviation of a bullet's longitudinal axis from the midline of flight trajectory (15). Energy is released at each tissue plane which may make the projectile change direction, fragment or tumble.

Direct tissue damage includes three key aspects: the prompt damage, the permanent wound tract, and the extravasation zone. Prompt damages include the initial direct crush/blunt injury from the projectile and are the main pattern of damage seen with low energy GSWs $(16,17)$. Secondly, the permanent wound tract includes the total permanent area of damage including ischemia from burn injury, direct crush injury, and cavitation. This can be challenging to identify upon initial presentation leading to over-debridement, particularly in high energy injuries $(18,19)$. Finally, the extravasation zone includes reversibly damaged tissue, hallmarked by edema and hemorrhage without macroscopic evidence of damage (11). In addition to these factors, debris or pieces of clothing may be embedded into the wound and cause additional damage and contamination.

In contrast to direct tissue injury, cavitation occurs in projectiles exceeding $600 \mathrm{~m} / \mathrm{s}$ resulting in extensive damage seen in high energy ballistic injuries. While it rarely occurs in civilian injuries, it may be present in hunting related injuries or those with high caliber weapons making it critical to assess the mechanism of injury. These high energy injuries are discussed in further detail later in this paper.

Key points:

* Ballistic injuries may be low or high energy, depending on projectile structure, velocity, and 
distance from which it is fired.

* Tissue damage can be direct, from prompt damage, the wound tract, and extravasation.

* Tissue damage can also be caused by cavitation, seen typically in high energy injuries.

\section{Patient evaluation}

Patient history is critically important in the assessment of genital trauma. It is vital to assess the mechanism of injury, including the caliber of ballistic weapon, as well as the potential for concomitant non-urologic injury which may occur in up to $70 \%$ of penetrating penoscrotal trauma $(3,20,21)$. While this information may not always be readily available, these variables should be gauged to tailor appropriate treatment when possible. Injuries to the thighs, pelvis, or buttocks are most common, and the patency of surrounding vasculature should be investigated if damage is suspected. Similarly, if the history or exam suggests or reveals a bladder injury, then a concomitant rectal injury should also be suspected or kept in mind. A focused physical examination should identify the locations of injuries, their depth, and the need for imaging.

The appropriate use and timing of imaging is one of the most controversial topics among penile/scrotal penetrating trauma. We recommend the use of CT urogram (CTU) with delayed picture (imaging can also be in the form of a plain X-ray 30 minutes later to look for extravasation) for any hemodynamically stable patients with suspected urologic injury to evaluate the entire GU tract (22). The history and exam and apparent wound trajectory are as always important. In the context of lower urinary tract and external genitalia injuries, the presence (but not exclusively the presence) of gross hematuria may warrant investigation for bladder and ureteric injury, and for this, CT cystogram would be most appropriate. Note should be made here that CT cystography requires sufficient distention of the bladder to achieve maximal sensitivity. This calls for clear and specific communication to the radiology team to ensure a false negative study does not result. Due to the prevalence of renal injuries and the risk of unrecognized ureteral injury to trauma patients, it is best to have a low threshold for CTU in the assessment of trauma patients. CTU has come to replace intravenous pyelogram, with rare exceptions such as centers without CT capabilities (22) Separate guidelines set forth by both the American Urological Association (AUA) and European Association of Urology (EAU) no longer recommend intravenous pyelogram as routine preoperative imaging in patients with penetrating abdominal trauma unless local factors of accessibility to CT force the need $(23,24)$. Further imaging may be appropriate based on the location of injury and its depth, but should never delay the treatment of other life threatening traumatic injuries (25).

Key points:

* History and physical exam are crucial in managing GSW of the genitalia.

* Findings should prompt further imaging as necessary.

\section{Penile injury}

When managing penetrating penile injuries, the goal is preservation and restoration of function and form. By minimizing bleeding and repairing damaged structures, risks of erectile and voiding dysfunction can be minimized while preserving cosmesis $(2,26,27)$. Up to $30 \%$ of injuries may be superficial, but assessment of damage to underlying structures such as the urethra and corporal bodies is critical in triaging who will need operative exploration $(22,27)$.

One of the first concerns in assessment of penile GSWs is in the integrity of the urethra. Urethral injury is present in $11-29 \%$ of penetrating penile injuries; initial exam should investigate any blood at the meatus, difficulty in catheter placement, nearby damage, or hematuria on voided urinalysis (5). Blood at the meatus has been consistently reported in $75 \%$ of patients with urethral injury $(27,28)$. Foley placement may be delayed if there is concern for injury or discontinuity of the urethra. Retrograde urethrogram (RUG) remains the mainstay in the diagnosis of urethral injuries with a sensitivity of $92 \%$ and specificity of $100 \%$ (27). Any stable patient with suspected urethral injury should undergo RUG (22). Classically, RUG has been recommended for all patients with a penetrating penile injury given the $50 \%$ rate of urethral injury reported by Miles et al. (29). However modern case series have demonstrated urethral injury in only $15-30 \%$ of patients, and multiple studies have shown it can be used more sparingly for superficial injuries if suspicion for urethral injury is low $(6,7,30)$ (Figures 1,2). Patients with very superficial injuries without blood at the meatus, spontaneously voiding without hematuria may forgo RUG with a low potential of missed injury $(27,30)$. If there is a high suspicion for urethral injury or bladder injury in a hemodynamically unstable patient, without availability of less invasive imaging (especially in the setting of concomitant injuries) it is necessary and 

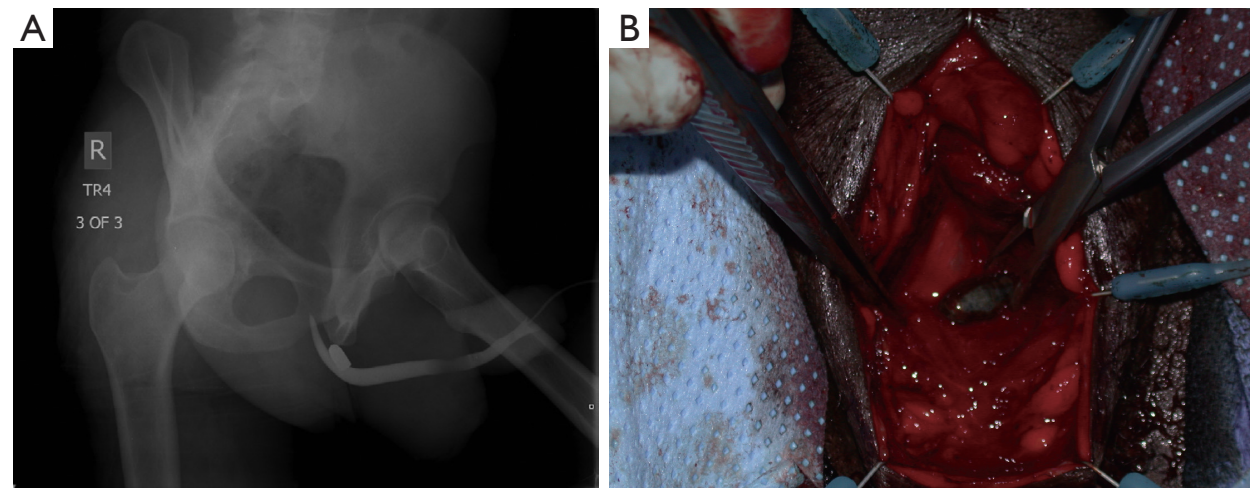

Figure 1 Urethrogram after GSW. (A) Retrograde urethrogram demonstrating bullet lodged near urethra; (B) operative exploration for bullet removal. Courtesy JB Myers. GSW, gunshot wound.
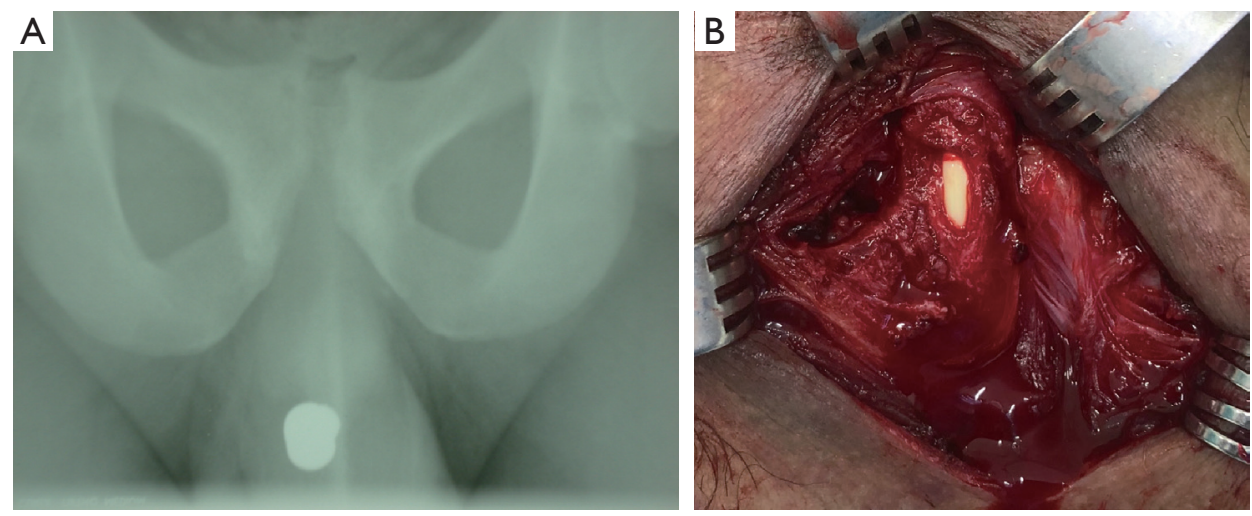

Figure 2 Urethral injury after GSW. (A) Bullet lodged in perineum; (B) identification of urethral injury caused by bullet. Courtesy A van der Merwe. GSW, gunshot wound.

reasonable to consider abdominal exploration for direct visualization of bladder injury and placement of suprapubic catheter $(23,31,32)$.

Cystogram may also be considered in certain cases. In patients with a high concern for pelvic or intraabdominal injury, CTU is recommended. If injury is noted or there are no exit wounds on physical exam, assessment of the bladder is more often done intraoperatively. However, in patients who do present with blood at the meatus with a negative RUG and no urgent need for intra-abdominal intervention, a cystogram may be valuable in locating the injury. After RUG is performed and deemed negative, catheter placement may precede CT cystogram for stable patients. Cystoscopy may be a good alternative as well in this setting, particularly if the patient presents with gross hematuria. Persistent gross hematuria despite large bore catheter placement should prompt evaluation with further imaging and endoscopy (cystoscopy and even proctoscopy) keeping in mind the possibility of concomitant vascular or rectal injury. Depending on these findings and severity, extraperitoneal or intraperitoneal abdominal exploration may be required for diagnosis and repair.

Once urethral injury is confirmed it is managed by either immediate primary repair or conservative non-operative management with immediate urinary diversion (26). Historic standard of care for penetrating urethral injuries was immediate urinary diversion with placement of a suprapubic tube (33-35). If strictures formed, they were later repaired in the outpatient setting. However, several large case series have shown that immediate primary repair of urethral GSWs results in a significantly lower stricture rate than diversion alone $(27,36,37)$. Primary watertight repair, preferably in a spatulated fashion, over a foley catheter using absorbable sutures allows minimal stricture 

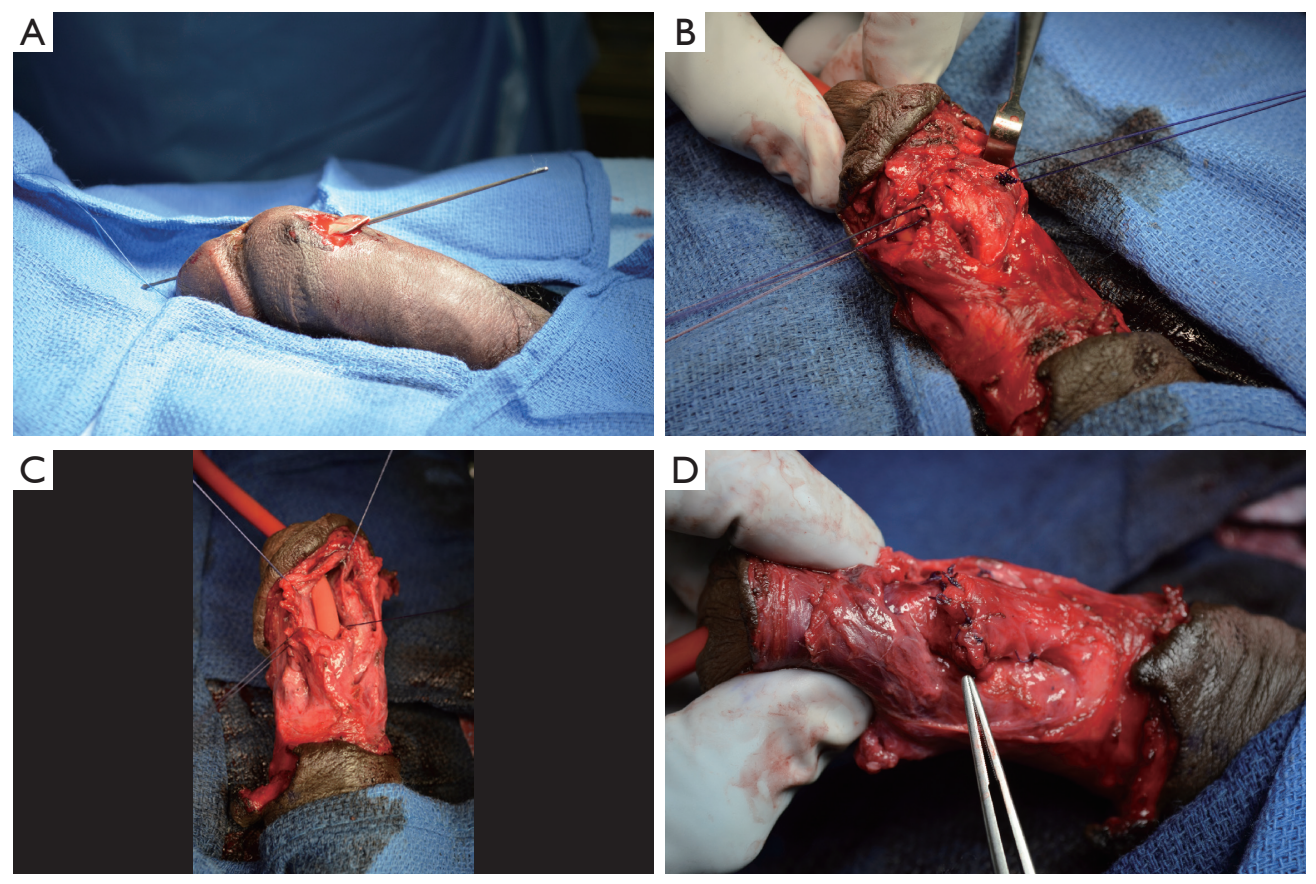

Figure 3 GSW of penis with corporal and urethral injuries. (A) Trajectory of penile GSW demonstrated using lacrimal probe; (B) penis degloved, corporal injury identified and repaired; (C) edges of urethral injury after debridement; (D) spatulated urethral repair. Courtesy K Venkatesan. GSW, gunshot wound.

formation (19) (Figure 3). This has resulted in a shift in the AUA and EUA urotrauma guidelines that now recommend prompt repair in uncomplicated cases of penetrating trauma to the anterior urethra $(23,24)$ (Table 1).

However, there may still be some patients who benefit from diversion with a delayed repair. Unstable patients who cannot tolerate anesthesia or require other operative interventions for concomitant injuries may not be able to undergo formal exploration and repair safely in the immediate setting. In some settings, delayed repair may be forced simply by the need for allocation of limited resources, where other patients requiring more acute care take precedence. Furthermore, it is the authors' anecdotal experience that in a highly select subset of patients, immediate diversion with delayed primary repair of the urethra 24-72 hours in stable patients with no other operative injuries may be possible and may be beneficial. This allows the injury time to mature, with a theoretical benefit of improved delineation of tissue viability as the "blast effect" evolves. Contused corpus spongiosum, which may appear compromised in the acute setting, may not become necrotic, and may recover, given its robust vascularity (5). This may also be the best course of action if a urologist or operating room is not available at the initial time of treatment. However, there are no large prospective or retrospective series evaluating this subacute delayed repair, and while there are some theoretical advantages named here, the data at this time clearly supports immediate primary repair for patients who are able to tolerate it.

Penetrating injuries of the posterior urethra may be rare and are best managed conservatively with diversion and some believe with endoscopic realignment of the urethra. Formal urethral reconstruction can then be performed in a delayed fashion-typically a minimum of 3 months-to repair a stenosis if one develops. Thus, a pursuit of complex urethroplasty in an emergent situation can be avoided $(7,19,30,38)$. If a rectal injury is present, posterior wounds should be managed with urinary diversion and attempted urethral closure with omental interposition. While it may not be mandatory, consideration should be given to diverting colostomy, presacral drainage, washout and rectal wound repair to prevent fistulation with the urethra during healing $(19,24)$.

The presence of a urethral injury and/or deep penetrating wound to the penis should raise suspicion for coexisting corporal injury. Further signs of corporal injury 
Table 1 Summary of American Urological Association (AUA) \& European Association of Urology (EAU) guidelines for penetrating genital trauma $(23,24)$

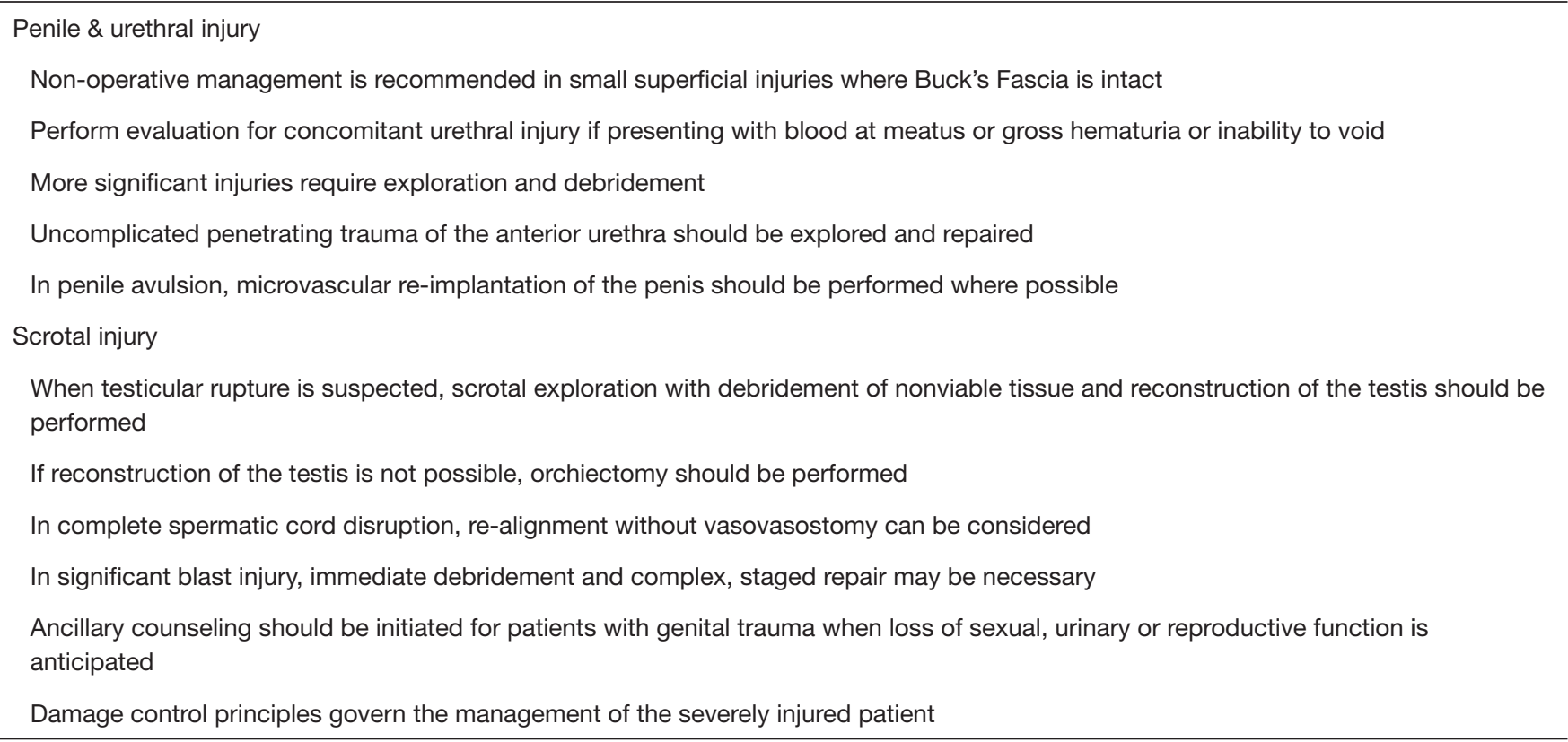

on exam may include a palpable corporeal defect, expanding hematoma, or uncontrolled bleeding of the penile shaft $(2,27)$. Deviation of the penis may occur in the opposite direction of the corporal defect secondary to an overlying hematoma (39). If corporal injury is suspected secondary to penetrating penile trauma, urgent operative exploration degloving and repair is critical to preserve erectile function (Table 1). Operative exploration should not be delayed for imaging such as penile ultrasound or MRI. In the setting of penetrating penile trauma there is little role for penile Doppler ultrasound. This is in contrast to blunt penile trauma where there are some data supporting the use of penile Doppler (such as evaluation of some penile fractures) (40). While cavernosography has been used in a few selected patients, it has shown to have several false negatives limiting its scope $(27,41)$. Similarly, MRI is rarely useful in the setting of acute penetrating penile trauma. While it can be used to evaluate the corpora in suspected penile fracture, it is less readily available, slower, more expensive, and can be challenging to interpret. It is safe to perform MRI in the setting of retained foreign bodies or bullet fragments, however if corporal injury is suspected most patients will require immediate exploration and repair. In the setting of a high index of suspicion for corporal injury, imaging should not delay intervention (42-45).

Penetrating trauma superficial to Buck's fascia may be irrigated with local debridement at bedside, avoiding extensive operative exploration (5). These very superficial penetrating traumas where there is low concern for urethral or cavernosal damage represent up to $30 \%$ of penetrating trauma in some studies $(2,5)$. However, the threshold for operative assessment and repair should be low for any penile GSW that appears deep to Buck's fascia or suspicious for urethral or cavernosal injury. A negative exploration may be less morbid than a missed injury.

Penile exploration has been described using a penoscrotal incision, or a subcoronal circumscribing incision with degloving $(6,27)$. Integrity of the corporal bodies is assessed by injecting saline into the cavernosa. Any areas of visible damage or leakage can be repaired using buried absorbable suture below Buck's fascia (44). Because of the variable position of the penis when injured, it is common to have complex bullet trajectories with multiple corporeal injuries resulting from a single gunshot. Immediate surgical interventions for corporal injury show an erectile dysfunction rate of $10-25 \%$ at four years, with one study demonstrating a peak rate of 54\% (45-49). Only $15 \%$ of 63 patients with penile GSW repaired by Kunkle et al. had erectile dysfunction, and all were responsive to pharmacotherapy (27). The vascularity of the penis works to its advantage in healing. Follow up is universally poor across civilian studies, in the authors' experience one third 


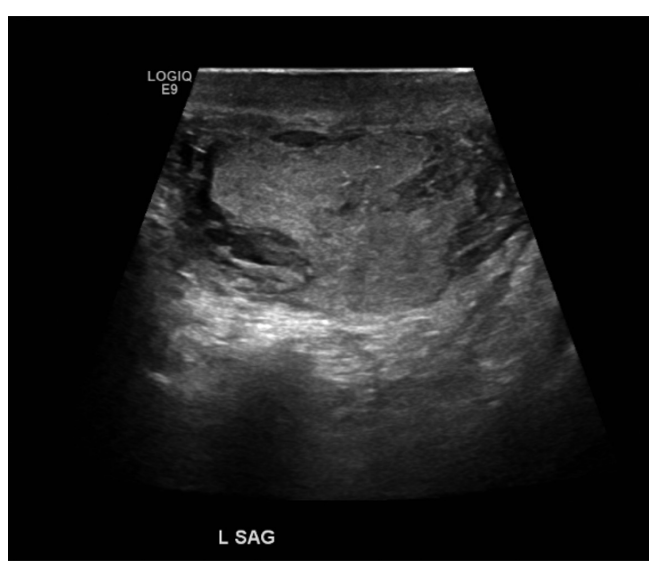

Figure 4 Ultrasound demonstrating testicular rupture. Violation of tunica albuginea integrity. Courtesy K Venkatesan.

of patients treated for GSW to the external genitalia were completely lost to follow up, and another third failed to follow up after their first appointment. It is imperative that patient counseling is thorough and consistent even in the initial patient interaction, advising on risks such as erectile dysfunction and urethral stricture. To effectively care for this population, the first follow-up appointment should stress patient education, with the assumption that patients will not return. Despite these barriers, large case series report good outcomes with potency and voiding with recovery of erection within six weeks postoperatively $(7,19,26,28)$.

Key points:

* The goal in managing penile injury is preservation of form and function.

* RUG is the mainstay in diagnosing urethral injury, and CT cystogram has utility if bladder injury is suspected.

* Prompt repair is recommended in uncomplicated anterior urethral injury.

* Posterior urethral injury should be treated with urinary diversion, but repair attempted if concomitant rectal injury.

* Any suspected corporal injury requires exploration and repair.

\section{Scrotal injury}

As with penile injuries, initial assessment of any scrotal injury should investigate the depth of the wound as well as the caliber and proximity of the weapon used. Physical exam is critical to determine if a patient has a deep injury requiring urgent operative management, and a cord block using lidocaine may be required to allow adequate examination (39). Often, patients present with gunshot injuries of the scrotum that are inadvertently self-inflicted, because their weapon was stored at hip level in a waistband or pocket and was discharged. While ultrasound has limited use in penetrating penile trauma, it is a mainstay in the assessment of patients with penetrating scrotal trauma in assessing for testicular injury with good sensitivity and specificity (50,51). Modern scrotal ultrasound can reliably evaluate the testes and its blood flow, the presence of any hematoma, and the integrity of the tunica albuginea (Figure 4). Superficial injuries, those without disruption of the deep dartos layer, may not need operative intervention if the testes are uninjured. If a patient has no other injuries that would require operation, scrotal ultrasound with Doppler can be very helpful to determine if the patient needs exploration by allowing the echodense tunica albuginea to be identified for disruption $(39,44)$. At times, scrotal swelling may make ultrasound assessment intolerable for the patient and suboptimal in visualization of the testes. In that setting, as well as when clothing or debris has been embedded even in low energy wounds, the scrotum should be explored (Table 1).

If there is no disruption or secondary ballistic injury to the testes, the superficial wounds itself can be treated with bedside local debridement and washout. Given the propensity for infection and the acceptable cosmetic results, wet to dry dressings with or without wide approximation of skin edges is recommended for these wounds. While large areas of injury with significant skin loss can be reapproximated using suture, formal closure or grafting are not recommended in the acute setting of civilian injuries.

In contrast, urgent operative exploration is necessary for patients who present with deep penetrating injury on initial assessment, or if such injury is demonstrated on scrotal ultrasound (5). When exploration is clearly indicated on clinical assessment alone, such as with deep penetrating injuries to the scrotum extending beyond the dartos, scrotal ultrasound should not delay operative intervention (7). Expanding scrotal hematomas, extrusion of testicular contents, or any acute or severe bleeding unresponsive to compression should also be evaluated in the operating room. A midline raphe incision or transverse mid scrotal incision is made and scrotum is investigated for injuries to the testes or their vascular structures $(2,19)$. Large hematomas should be drained and any sources of bleeding ligated, as there is 

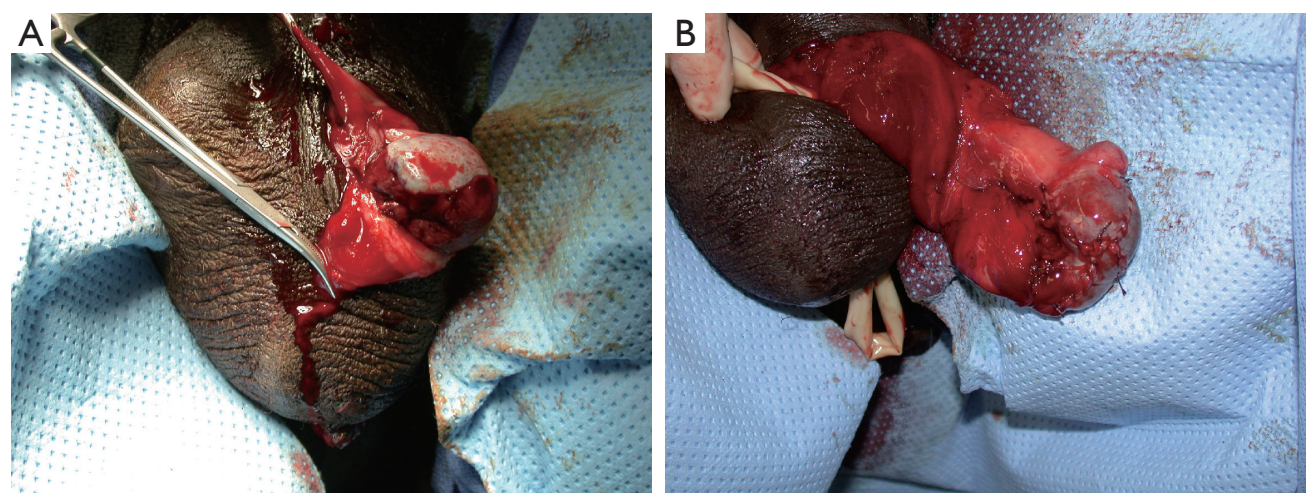

Figure 5 Identification and repair of GSW causing testicular rupture. (A) Injured testis exposed; (B) repaired testis. Courtesy JB Myers. GSW, gunshot wound.

limited ability for scrotal bleeds to tamponade themselves and increased pressure may cause later testicular atrophy (44,52-54). While only demonstrated in blunt trauma, patients with intra-testicular hematoma fare better with exploration, as many will have pain or infection resulting in eventual orchiectomy. In addition to the testes themselves, the spermatic cords should be assessed bilaterally for a pulse or Doppler flow of the testicular artery, as it is possible to have spermatic cord injury on one side and concomitant injury to the contralateral testis. Any disrupted vas should be tied off with nonabsorbable suture to allow identification for vasovasotomy later (30). If injury to the testes is identified, the testicle may be salvaged by debriding the seminiferous tubules and closing the tunica albuginea with small absorbable suture such as 4-0 polyglactin. Large case series have demonstrated that $35-50 \%$ of injured testicles can be salvaged by this method $(7,30,51)$ (Figure 5$)$. While the goal of scrotal exploration is testicular preservation, extensive injuries to the testicular hilum, spermatic cord, or catastrophic shattering of testis itself warrant orchiectomy at the time of exploration. While bilateral scrotal injuries occur in up to $31 \%$ of patients (53), deeper injury to the testes is rare bilaterally $(7-11,30,51,53)$ (Figure 6). Efforts should be made to preserve as much testicular parenchyma as possible to maintain normal testosterone levels and in many cases sperm production $(2,19,30,55)$. Urgent fertility consultation should be considered in patients who require bilateral orchiectomy. The scrotum can be closed using vertical mattress suture with a Penrose drain left in place for 24 hours and postoperative gram-positive organism coverage (44).

Key points:

* Ultrasound assessment is a mainstay of diagnosis of testis injury: disruption of the tunica albuginea should prompt scrotal exploration.

* Bilateral injuries are common and any suspicion of bilateral testis injury warrants exploration of the contralateral testis.

* Every effort should be made to spare the testis including debridement of seminiferous tubules and primary closure of disruption of the tunica albuginea.

\section{High-energy injury (military bullets, IED/land mine/blast injury)}

Injuries to the external genitalia are present in around $70 \%$ of combat related GU injuries and up to $5 \%$ of all military traumas $(14,56,57)$. Penetrating injuries secondary to GSWs or blasts are the predominant type of trauma seen in the external genitalia in the military setting. Coexisting injuries to other organ systems occur with high energy projectiles in $80-96 \%$ of cases $(56,58)$. Despite a period of relative global peace with low numbers of people killed in war in the early 2000s, the past two decades have shown a dramatic increase in civilian war deaths and disabilities due to global conflict. GU injury rates to military personnel increased from $7.2 \%$ to $12.7 \%$ in the US military personnel between 2009 and 2010 (59). The upward blast of hidden explosives and improvised explosive devices (IED) puts the lower extremities and external genitalia at particularly high risk of blast injury with limited protection compared to the torso (57,60-62).

Military conflict is marked by higher energy wounds secondary to higher caliber weapons as discussed in wound ballistics above. These high energy projectiles are marked by a temporary cavity that leads to massive tissue destruction 

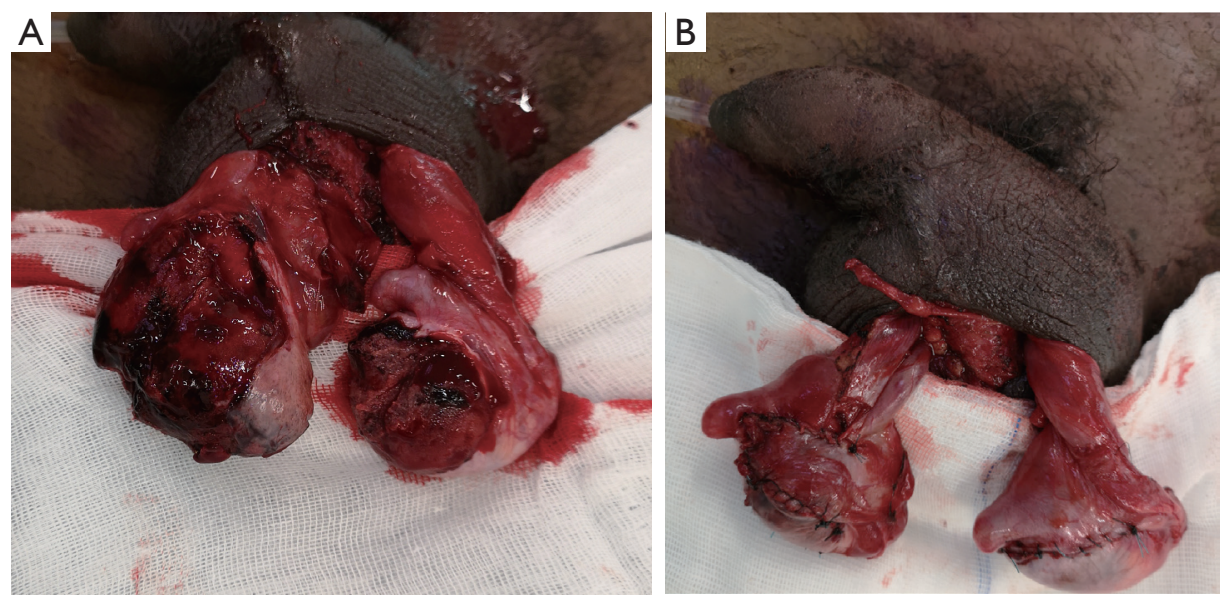

Figure 6 Management of bilateral testicular injury. (A) Bilateral testicular injury from single GSW; (B) right testis repaired with tunica vaginalis flap. Left testis primary repair of tunica albuginea. Courtesy D du Plessis \& A. van der Merwe.

(1,12-16). Conservative treatments are not feasible options as they are in the civilian setting, most patients are taken to the operating room immediately to achieve appropriate hemostasis, debride and repair damaged structures. Wound debridement of devitalized tissue is a critical aspect of early management of high energy injuries, given their large zone of damage. Once patient's other injuries are stabilized, high energy penetrating injuries to the external GU tract are best managed in the operating room. Immediate low-pressure irrigation should be used to wash away contamination and debris, and any actively bleeding vessels should be ligated (63). Irrigation is particularly important in the setting of blast and shotgun wounds where pellets, powder grains, shrapnel and other foreign materials may be present in the wound tract. Multiple debridements are often needed to address evolving devitalized tissue in the permanent wound tract and extravasation zones with care not to overdebride tissues that may recover (12-14). Questionably viable tissues are left to subsequent debridement, as they are often salvageable given the vascularity of the external genitalia (14). Evaluation of the deep structures of the penis and scrotum should then be performed. Once all necrotic tissue has been debrided away to prevent infection, the wound is allowed to heal with planned staged reconstruction often a matter of months later (Table 1).

In Operation Iraqi Freedom (OIF), repair of penile and scrotal injuries was the most frequently performed surgical procedure (57). Penile injuries demonstrated extensive genital skin and soft tissue loss that mandated multiple returns to the OR and staged repairs. Soft tissue defects were further managed using negative pressure wound vac therapy, or split thickness skin grafting once granulation beds had evolved. These high velocity injuries are much more likely to require reoperation than civilian GSWs (57). Three patients described by Hudak demonstrated high velocity penile GSWs that spared the urethra, but with extensive loss of penile skin showed delayed necrosis after corporal repair and skin coverage, requiring serial debridement and eventual partial penectomy. While grafting may be necessary in the long term setting, this should not be done in the initial surgical repair until the wound has matured (63). Furthermore, while half of patients only required debridement and repair of superficial injuries in OIF, 46\% demonstrated urethral or corporal injuries requiring penoplasty or corporoplasty (57). High energy wounds to the corporal bodies can cause hemorrhage, that can be (although rarely are) life threatening. Hemostasis can be achieved by repairing the tunica albuginea, as sutures deep within the corpora may affect erectile tissues with minimal hemostatic benefit. Additionally, glans injuries are common due to shearing trauma from upward blast injuries. Primary closure may be used for small glans injuries or debridement with reshaping of the glans for larger injuries with $<50 \%$ of the glans involved (14). Injuries involving more than half of the glans may require grafting from split thickness skin grafts, or buccal mucosa grafts which can be used in a multistage repair to form a new meatus with a neourethra.

Distinct from other penetrating injuries, traumatic amputation or avulsion of the penis or scrotum by a 
projectile are the most severe. These injuries are rare among civilian trauma injuries; up to $50 \%$ may be self-inflicted or accidental and can also occur from industrial or agricultural accidents, however they are more commonly reported in military blast trauma $(3,5,20,51,64-67)$. Penile avulsions should be taken to the OR immediately for debridement, primary repair, and urinary diversion to assess if primary reanastomosis is possible. If the severed penis is present on initial presentation, it should be wrapped in saline soaked gauze and placed in a biohazard or plastic bag. That bag is placed in a second bag filled with saline to create a barrier against freezing, and the second bag is then placed on ice. While the method of repair must be tailored to surgeon experience, the best outcomes are seen with microsurgical re-anastomosis within twelve hours of ischemia (66-69) (Table 1). Microsurgical re-anastomosis of the deep dorsal vein, dorsal artery and nerve produces the lowest rates of penile sensation loss, infection, and urethral stricture, with up to $50 \%$ return of erectile function) $(67,69,70)$. Shunts may also be used to maximize graft viability (71). If reanastomosis is not possible due to prolonged ischemic time or lack of the native phallus, the wound should be closed to allow future reconstruction, with urinary diversion and control of any other injuries. Depending on the amount of avulsed tissue and whether the corpora, scrotum or testes is intact, a method of delayed reconstruction using forearm free flap has been demonstrated by Rashid et al. in 35 men with high patient satisfaction (68). Recruitment of external pudendal blood supply may also be necessary to help prevent skin necrosis of the salvaged penile shaft (72). The challenge here, in addition to the microvascular anastomosis and delays from injury to repair, includes potential damage to the tissue surrounding the penis. This, depending on the severity, may present a significant and possibly insurmountable obstacle to re-implantation of the penis.

The low dependent nature of the scrotum makes it especially susceptible to penetrating trauma in wartime. During the civil conflicts of Bosnia-Herzegovina, 26\% of patients sustained scrotal injuries compared to $9.5 \%$ with penis injuries (73). In US military members in the Iraqi civil war, $31 \%$ presented with penile injuries, 55.6\% presented with scrotal injuries, and $33 \%$ presented with testicular injury (74). High energy scrotal injuries can be debrided more aggressively than penile injuries given the excess soft tissue of the scrotum (14). However, unlike in low energy settings, visible appearance of the scrotum alone is unreliable in high energy projectile injury, as significant damage such as testicular rupture may result from what appear to be small superficial lacerations $(56,57)$. Scrotal exploration should be routine for all penetrating injuries to the scrotum in the military setting. Testicular damage is more commonly bilateral than in the civilian population, often with one testicle demonstrating tissue loss while the other is merely contused (62). While $90 \%$ of testicular injuries were treated with orchiectomy in the Vietnam era, salvage rates have consistently been reported at or above $50 \%$ in modern military data comparable to the civilian population $(1,5,16,56,57)$.

Key points:

* High energy injuries cause massive tissue damage by cavitation effect.

* Conservative management is rarely feasible in this setting, and prompt exploration and debridement should be undertaken.

* Staged repair may be necessary depending on the extent of damage.

* Penile avulsion requires immediate debridement and urinary diversion, and when possible, microvascular repair.

* Scrotal exploration is necessary for all high-energy, military setting injuries.

\section{Limitations and areas of debate}

Most recommendations in GSW management do not attract controversy, but there are still some varied opinions and debate about the timing of reconstruction, particularly in high energy injuries. The data, overall, tends to favor delayed reconstruction in most cases. This brings to light one of the main limitations of reviewing and practicing GSW management: the variables surrounding these injuries are innumerable, meaning real-life situations may not replicate those in text, and may not conform to planned, systematic principles of care. Conversely, the chaotic nature of these injuries also makes them more difficult to systematically organize into pathways with clear decision points.

In that vein, most studies referenced here are accordingly retrospective in nature, with the inherent limitations therein. Since trauma management is not easily amenable to randomization or prospective study, evolution or innovation in management is more difficult to bring about in an evidence-based fashion. Progress will most likely be found in multi-disciplinary approaches with trauma surgeons and plastic reconstructive surgeons, as well as in multi-institutional efforts to examine larger, aggregate experiences. 


\section{Conclusions}

Assessment of the mechanism of GSW and energy of the ballistic is critical to appropriately treating GSWs in the civilian and military setting. In the civilian setting, a third of patients with superficial injuries may only need local wound care; CTU, cystogram, RUG and scrotal ultrasound can be helpful tools in the evaluation of a patient's operative needs depending on damage to deeper structures. Patients with injuries deep to the dartos or Buck's fascia will likely need operative exploration and repair. Primary repair of the urethra is the current standard of care for low energy GSWs. The vascularity of the external genitalia allows excellent recovery from trauma.

High energy wounds cause more extensive damage to GU tissues and while available imaging may be helpful, these wounds should almost exclusively be assessed in the operating room. Most high energy wounds will need multiple explorations with serial debridement and later staged repair. Even superficial high energy penetrating trauma to the scrotum should always be assessed in the operating room as hidden testicular damage is not uncommon. Testicular tissue should be salvaged whenever possible in the civilian and military setting.

\section{Acknowledgments}

Funding: None.

\section{Footnote}

Provenance and Peer Review: This article was commissioned by the Guest Editors (Francisco E. Martins and Tobias S. Köhler) for the series "Controversies and Considerations of Penile Surgery" published in Translational Andrology and Urology. The article has undergone external peer review.

Reporting Checklist: The authors have completed the Narrative Review Reporting Checklist. Available at: http:// dx.doi.org/10.21037/tau-20-1175

Conflicts of Interest: All authors have completed the ICMJE uniform disclosure form (available at http://dx.doi. org/10.21037/tau-20-1175). The series "Controversies and Considerations of Penile Surgery" was commissioned by the editorial office without any funding or sponsorship. JBM is an unpaid editorial board member of Translational Andrology and Urology from Dec 2017-July 2022. The authors have no other conflicts of interest to declare.
Ethical Statement: The authors are accountable for all aspects of the work in ensuring that questions related to the accuracy or integrity of any part of the work are appropriately investigated and resolved.

Open Access Statement: This is an Open Access article distributed in accordance with the Creative Commons Attribution-NonCommercial-NoDerivs 4.0 International License (CC BY-NC-ND 4.0), which permits the noncommercial replication and distribution of the article with the strict proviso that no changes or edits are made and the original work is properly cited (including links to both the formal publication through the relevant DOI and the license). See: https://creativecommons.org/licenses/by-nc-nd/4.0/.

\section{References}

1. Selikowitz SM. Penetrating high-velocity genitourinary injuries. Part II: Ureteral, lower tract, and genital wounds. Urology 1977;9:493-9.

2. Brandes SB, Buckman RF, Chelsky MJ, et al. External genitalia gunshot wounds: a ten-year experience with fiftysix cases. J Trauma 1995;39:266-71.

3. García-Perdomo HA. Importance of defining the best treatment of a genital gunshot wound: A case report. World J Clin Cases 2014;2:587-90.

4. Bjurlin MA, Kim DY, Zhao LC, et al. Clinical characteristics and surgical outcomes of penetrating external genital injuries. J Trauma Acute Care Surg 2013;74:839-44.

5. Phonsombat S, Master VA, McAninch JW. Penetrating external genital trauma: a 30-year single institution experience. J Urol 2008;180:192-5.

6. Cerwinka WH \& Block NL. Civilian gunshot injuries of the penis: the Miami experience. Urology 2009;73:877-80.

7. Cline KJ, Mata JA, Venable DD, et al. Penetrating trauma to the male external genitalia. J Trauma 1998;44:492-4.

8. McGeady JB, Breyer BN. Current epidemiology of genitourinary trauma. Urol Clin North Am 2013;40:323-34.

9. Salvatierra O Jr, Rigdon WO, Norris DM, et al. Vietnam experience with 252 urological war injuries. J Urol 1969;101:615-20.

10. Serkin FB, Soderdahl DW, Hernandez J, et al. Combat urologic trauma in US military overseas contingency operations. J Trauma 2010;69 Suppl 1:S175-8.

11. Stefanopoulos PK, Hadjigeorgiou GF, Filippakis K, et al. Gunshot wounds: A review of ballistics related to penetrating trauma. J Acute Dis 2014;3:178-85. 
12. Bartlett, CS Clinical update: gunshot wound ballistics. Clin Orthop Relat Res 2003;408:28-57.

13. Bartlett CS, Helfet DL, Hausman MR, et al. Ballistics and gunshot wounds: effects on musculoskeletal tissues. J Am Acad Orthop Surg 2000;8:21-36.

14. Williams M, Jezior J. Management of combat-related urological trauma in the modern era. Nat Rev Urol 2013;10:504-12.

15. Selikowitz SM. Penetrating high velocity genitourinary injuries. Urology 1977;9:371-6.

16. Stefanopoulos PK, Filippakis K, Soupiou OT, et al. Wound ballistics of firearm-related injuries--part 1: missile characteristics and mechanisms of soft tissue wounding. Int J Oral Maxillofac Surg 2014;43:1445-58.

17. Dougherty PJ, Najibi S, Silverton C, et al. Gunshot wounds: epidemiology, wound ballistics, and soft-tissue treatment. Instr Course Lect 2009;58:131-9.

18. Santucci RA, Chang YJ. Ballistics for physicians: myths about wound ballistics and gunshot injuries. J Urol 2004;171:1408-14.

19. Bandi G, Santucci RA. Controversies in the management of male external genitourinary trauma. J Trauma 2004;56:1362-70.

20. Wessells H, Long L. Penile and genital injuries. Urol Clin North Am 2006;33:117-26.

21. Holmes JF. Genitourinary trauma. Trauma: A Comprehensive Emergency Medicine Approach. Cambridge University Press, 2011:232-50.

22. Dane B, Baxter AB, Bernstein MP. Imaging genitourinary trauma. Radiol Clin North Am 2017;55:321-35.

23. Morey AF, Brandes S, Dugi DD, et al. Urotrauma: AUA guideline. J Urol 2014;192:327-35.

24. Kitrey ND, Djakovic N, Kuehhas FE, et al. Guidelines on Urological Trauma. EAU Guidelines. Edn. Presented at the EAU Annual Congress Copenhagen, 2018.

25. Nagy KK, Brenneman FD, Krosner SM, et al. Routine preoperative "one-shot" intravenous pyelography is not indicated in all patients with penetrating abdominal trauma. J Am Coll Surg 1997;185:530-3.

26. Hall SJ, Wagner JR, Edelstein RA, et al. Management of gunshot injuries to the penis and anterior urethra. J Trauma 1995;38:439-43.

27. Kunkle DA, Lebed BD, Mydlo JH et al. Evaluation and management of gunshot wounds of the penis: 20year experience at an urban trauma center. J Trauma 2008;64:1038-42.

28. Goldman HB, Dmochowski RR, Cox CE. Penetrating trauma to the penis: functional results. J Urol 1996;155:551-3.

29. Miles BJ, Poffenberger RJ, Farah RN, et al. Management of penile gunshot wounds. Urology 1990;36:318-21.

30. Gomez RG, Castanheira AC, McAninch JW.

Gunshot wounds to the male external genitalia. J Urol 1993;150:1147-9.

31. Wessells H, Angermeier KW, Elliott SP, et al. American Urological Association (AUA) Guideline American Urological Association Male Urethral Stricture. AUA Clin Guidel 2016;1-34.

32. Lynch TH, Martínez-Piñeiro L, Plas E, et al. EAU guidelines on urological trauma. Eur Urol 2005;47:1-15.

33. Morehouse DD. Emergency management of urethral trauma. Urol Clin North Am 1982;9:251-4.

34. Pontes JE, Pierce JM Jr. Anterior urethral injuries: four years of experience at the Detroit General Hospital. J Urol 1978;120:563-4.

35. Waterhouse K, Gross M. Trauma to the genitourinary tract: a 5-year experience with 251 cases. J Urol 1969;101:241-6.

36. Husmann DA, Boone TB, Wilson WT. Management of low velocity gunshot wounds to the anterior urethra: the role of primary repair versus urinary diversion alone. J Urol 1993;150:70-2.

37. Cavalcanti AG, Krambeck R, Araujo A, et al. Penile lesion from gunshot wound: a 43-case experience. Int Braz J Urol 2006;32:56-60.

38. Mohr AM, Pham AM, Lavery RF, et al. Management of trauma to the male external genitalia: the usefulness of American Association for the Surgery of Trauma organ injury scales. J Urol 2003;170:2311-5.

39. Bertini JE, Corriere JN. Male genital trauma: Evaluate promptly, treat with restraint. Contemp Urol 1992;4:13.

40. Dell'Atti L. The role of ultrasonography in the diagnosis and management of penile trauma. J Ultrasound 2016;19:161-6.

41. Mydlo JH, Hayyeri M, Macchia RJ. Urethrography and cavernosography imaging in a small series of penile fractures: a comparison with surgical findings. Urology 1998;51:616-9.

42. Dedini RD, Karacozoff AM, Shellock FG, et al. MRI issues for ballistic objects: information obtained at 1.5-, 3and 7-Tesla. Spine J 2013;13:815-22.

43. Antonini G, Vicini P, Sansalone S, et al. Penile fracture: penoscrotal approach with degloving of penis after Magnetic Resonance Imaging (MRI). Arch Ital Urol Androl 2014;86:39-40.

44. Monga M, Moreno T, Hellstrom WJ. Gunshot wounds to the male genitalia. J Trauma 1995;38:855-8.

45. El-Assmy A, El-Tholoth HS, Abou-El-Ghar ME, et al. Risk factors of erectile dysfunction and penile vascular changes after surgical repair of penile fracture. Int J Impot 
Res 2012;24:20-5.

46. Hatzichristodoulou G, Dorstewitz A, Gschwend JE, et al. Surgical management of penile fracture and longterm outcome on erectile function and voiding. J Sex Med 2013;10:1424-30.

47. Raheem AA, El-Tatawy H, Eissa A, et al. Urinary and sexual functions after surgical treatment of penile fracture concomitant with complete urethral disruption. Arch Ital Urol Androl 2014;86:15-9.

48. Pavan N, Tezzot G, Liguori G, et al. Penile fracture: retrospective analysis of our case history with long-term assessment of the erectile and sexological outcome. Arch Ital Urol Androl 2014;86:359-70.

49. Tamhankar AS, Pawar PW, Sawant AS, et al. Fractured penis: not so rare! Urol Int 2017;99:63-8.

50. Churukanti GR, Kim A, Rich DD, et al. Role of ultrasonography for testicular injuries in penetrating scrotal trauma. Urology 2016;95:208-12.

51. Simhan J, Rothman J, Canter D, et al. Gunshot wounds to the scrotum: a large single-institutional 20-year experience. BJU Int 2012;109:1704-7.

52. Cass AS, Ferrara L, Wolpert J, et al. Bilateral testicular injury from external trauma. J Urol 1988;140:1435-6.

53. Cass AS. Immediate radiological evaluation and early surgical management of genitourinary injuries from external trauma. J Urol 1979;122:772-4.

54. Wasko R, Goldstein AG. Traumatic rupture of the testicle. J Urol 1966;95:721-3.

55. Pohl DR, Johnson DE, Robison JR. Bilateral testicular rupture: report of a case. J Urol 1968;99:772-3.

56. Waxman S, Beekley A, Morey A, et al. Penetrating trauma to the external genitalia in Operation Iraqi Freedom. Int J Impot Res 2009;21:145-8.

57. Hudak SJ, Hakim S. Operative management of wartime genitourinary injuries at Balad Air Force Theater Hospital, 2005 to 2008. J Urol 2009;182:180-3.

58. Tillet JW, Carney JK. Gunshot Wounds of the Male External Genitalia: AUA Update Series. American Urological Association, Education and Research Inc., Linthicum, MD 2008;5:27.

59. Ficke JR, Eastridge BJ, Butler FK, et al. Dismounted complex blast injury report of the army dismounted complex blast injury task force. J Trauma Acute Care Surg 2012;73:S520-34.

60. Paquette EL. Genitourinary trauma at a combat support hospital during Operation Iraqi Freedom: the impact of body armor. J Urol 2007;177:2196.

61. Owens BD, Kragh JF Jr, Wenke JC, et al. Combat wounds in operation Iraqi Freedom and operation Enduring
Freedom. J Trauma 2008;64:295.

62. Banti M, Walter J, Hudak S, et al. Improvised explosive device-related lower genitourinary trauma in current overseas combat operations. J Trauma Acute Care Surg 2016;80:131-4.

63. Balzano FL, Hudak SJ. Military genitourinary injuries: past, present, and future. Transl Androl Urol 2018;7:646-52.

64. Perovic SV, Djinovic RP, Bumbasirevic MZ, et al. Severe penile injuries: a problem of severity and reconstruction. BJU Int 2009;104:676-87.

65. Morey AF, Metro MJ, Carney KJ, et al. Consensus on genitourinary trauma: external genitalia. BJU Int 2004;94:507-15.

66. Virasoro R, Tonkin JB, McCammon KA, et al. Penile Amputation: Cosmetic and Functional Results. Sex Med Rev 2015;3:214-22.

67. Santucci RA, Bartley JM. Urologic trauma guidelines: a 21st century update. Nat Rev Urol 2010;7:510-9.

68. Rashid M, Sarwar SU. Avulsion injuries of the male external genitalia: classification and reconstruction with the customized radial forearm free flap. Br J Plast Surg 2005;58:585-92.

69. Jordan GH. Management of penile amputation. Emergencies in Urology. Berlin: Springer, 2007;270-5.

70. Bhatt YC, Vyas KA, Srivastava RK, et al. Microneurovascular reimplantation in a case of total penile amputation. Indian J Plast Surg 2008;41:206-10.

71. Fuoco M, Cox L, Kinahan T. Penile amputation and successful reattachment and the role of winter shunt in postoperative viability: A case report and literature review. Can Urol Assoc J 2015;9:E297-9.

72. Tuffaha SH, Budihardjo JD, Sarhane KA, et al. Expect skin necrosis following penile replantation. Plast Reconstr Surg 2014;134:1000e-1004e.

73. Hudolin T, Hudolin I. Surgical management of urogenital injuries at a war hospital in Bosnia-Hrzegovina, 1992 to 1995. J Urol 2003;169:1357-9.

74. Janak JC, Orman JA, Soderdahl DW, et al. Epidemiology of genitourinary injuries among male U.S. service members deployed to Iraq and Afghanistan: Early findings from the Trauma Outcomes and Urogenital Health (TOUGH) Project. J Urol 2017;197:414-9.

Cite this article as: Goldman C, Shaw N, du Plessis D, Myers JB, van der Merwe A, Venkatesan K. Gunshot wounds to the penis and scrotum: a narrative review of management in civilian and military settings. Transl Androl Urol 2021;10(6):2596-2608. doi: $10.21037 /$ tau-20-1175 